\title{
Inclusion in Education and in Public Debates on Education
}

\author{
Marianna Papastephanou \\ Department of Education, University of Cyprus \\ edmari@ucy.ac.cy
}

\begin{abstract}
Inclusion is nowadays a most cherished notion in educational discourses and policies around the globe. Discourses of inclusion appear as the most humane, politically sensitive and praiseworthy heights that political thought and educational practice can reach. At the same time, a kind of inclusion in the public sphere is enacted whenever people freely join debates on matters of general interest, educational or other. For, participation in debates on education and on teacher education is not limited to educational researchers, teacher organizations and all those involved in educational theory and practice. The present article begins with the operations of inclusion in educational theory and discusses some complicities and risks lurking in the unqualified valorization of inclusion that is noticeable in educational discourses and in public debates on education and teachers' performance. Such valorization operates inter alia at the expense of thoughtful withdrawal and pertinent self-exclusion. In societal debates on education, inclusion as unconditional prerogative of a narcissist I (eye) or as social interpellation to participate legitimizes just everybody's having investigative relevance to issues of education. The article ends with some suggestions concerning the positioning of inclusion within a broader set of concepts required for a desirable redirection of educational discourses and policies.
\end{abstract}

\section{Keywords}

diversity - exclusion - power - democracy - discourse - membership - participation marginalization 
Inclusion is a valued notion in much philosophy, political education and public sphere today. Discourses of inclusion evoke a humanist perspective on a right to membership in just any collectivity or activity that may attract a social agent. The act of including becomes for political communities and educational practices the foremost token or credential of political correctness and sensitivity. The implicit idea is that, if we manage to cultivate tendencies toward including any possible other within our communities, debates, institutions and practices, we have shown due respect and fulfilled our ethico-political obligations towards alterity. A concomitant assumption is that, in so doing, we surpass older developmental stages of humanity and we advance toward new desirable states of political and educational organization, leaving behind all those backward elements of society that effect discrimination, oppression and marginalization. In other words, inclusion has become a political ideal invested with a modernist, soteriological passion for the new and the redemptive, that which, if applied, will bring about liberation from pathologies. Inclusion has thus obtained the status of a utopianized endpoint, a set destination of educational and political-philosophical ventures.

The term 'inclusion' exerts a remarkable rhetorical power, not just in the field of educational studies that includes the predicate 'inclusive', that is, in 'inclusive education', but also and more generally in all current academia, educational and other and in the public sphere more or less globally. Using or mentioning the word 'inclusion' sometimes operates in ways that reflect back on the user and grant her a favorable moral image. By declaring her commitment to inclusive talk and through vehement, verbal renunciation of exclusion, the scholar, the educationist or the policy maker gives credentials of progressivism and concern for otherness. Regardless of intentions or regardless of awareness of inclusion-use effects, the academic thus obtains her own inclusion in the community of researchers worthy of the name. Likewise, the administrator and the politician establish a positive public image that secures them membership, i.e., inclusion, in the category of progressive and democratic leaders. This operation of safe and protected progressive self-descriptions, which deep down benefits the social agent rather than exposing her to any theoretical or practical challenge and thought-provocation, is accompanied by a paradoxical and as yet unnoticed implication: the obsessive and facile attachment to inclusion results in various exclusions. I will refer to such exclusions as we go along. But let me first state the argument of this article and my steps for deploying it. 
Inclusion is taken for granted as a prerogative and is even glorified, but, in some cases, this entails major political complicities. The present article questions the fashionable, unconditional praise of inclusion that is detectable when inclusion is elevated to an unqualified aim in education and when just any public intervention in debates on education is legitimized as proof of an inclusive, democratic and open society.

This argument needs disclaimers: I do not argue that inclusion is undesirable or that people should be excluded from public debates. I vehemently reject exclusivist practices by which some agents are silenced or left out. Nor am I saying that because inclusion plays a part in current academic and extramural distributions of power (e.g. securing academic visibility and citability, creating new agents of policy shaping, etc.) this is enough for discrediting it as a normative and educationally worthwhile term. My argument is that inclusion is an important ethico-political ideal for education and for society (local and global), but it cannot cover the whole ground of educational and political normativity and it should not be utopianized. Its ambiguities should be acknowledged and researched. When exaggerated, when inclusion as a theoretical imperative and practical requirement stands out in an unreflective manner, it is promoted at the high cost of our neglecting other normative tasks, also at the cost of discursively excluding other notions and challenges of selfhood and, ultimately, of putting a full stop at political education too soon, as if all that such an education has to accomplish is just to assist the inclusion of people to whatever the hosting frame might be. Thus, in this article, I target general, uncritical and unqualified glorifications of inclusion and not cautious and balanced engagements with this notion. My argument will not be directed at the field of 'Inclusive Education' but at the more common use of inclusion as a cherished educational aim and as an undisputed political value with specific effects on communicative and institutionalized power.

My first step involves brief comments on inclusion, its employment and its operations in educational discourses. Then I deploy my critique from a philosophical perspective, ${ }^{1}$ using as a relevant example the recurrent, neoliberal interventions in what counts as worthy education (teacher education notwithstanding). I will use this example because the contemporary public sphere considers the teacher a 'crucial influence in education for inclusion' and for 'the development of the inclusive school' (Reynolds, 2001, 466). I conclude with the suggestion that our engagement with inclusion requires some critical revisiting and some consideration of what our fixation on inclusion may exclude.

1 In an effort to engage more inclusively with philosophical idioms, this article will adopt a mixed philosophical style that comprises both analytic and continental modalities. 
Inclusion in its current sense is a concept of the modern European vocabulary, as its early uses date back to the $17^{\text {th }}$ century. It comes from the Latin includere which interestingly means to 'shut in', to 'shut something up' and to 'confine.. ${ }^{2}$ In its current English signification, the noun 'inclusion' may refer to an addition or annex to a group or set (e.g. this $\mathrm{PhD}$ student is a new inclusion in this year's Postgraduate Course). Or, more commonly, it refers to the act of adding or annexing to a group anything external or foreign. ${ }^{3}$ In current academia, inclusion is mostly employed when the other to be included has been a subject or collectivity whose rightful membership within a totality has long been either neglected or disputed and blocked. Hence, as one commentator writes, 'inclusion is associated with issues of race, ethnicity, disability and gender' (Dunne, 2009, p. 43). ${ }^{4}$

Indeed, inclusion emerges as a normativity sanctioned in virtue of the risks that marginalizing and discriminatory practices entail for democracy: 'if a democratic will formation is crucial, we are invited to question the processes of marginalization now playing out within and beyond the classroom' (Strand, 2015, p. 179). Therefore, 'within the international context', inclusive education 'is seen more broadly as a reform that supports the diversity among all learners' and aims at 'eliminating social exclusion' (Peters and Besley, 2014, p. 109). The latter 'is a consequence of attitudes and responses to diversity in race, social class, ethnicity, religion, gender and ability' (109).

At first sight, inclusion and its antonym, exclusion, appear as logical and mathematical relations of set and subsets. A set has subsets, sets and subsets have members; membership in a set or in a subset is based on criteria and rules of relevance or commonality. For sets, and subsets to exist, something must inevitably be excluded from them. But such relations become politicized when numbers matter, when numerical relations reflect a social ontology (who counts, who is of essence, who remains invisible, who is thought to inhabit a space rightfully, etc.) and are associated with conditions of membership, treatment of otherness and outlook on what passes as the 'strange' and

2 See, for instance, the Online Etymological Dictionary, https://www.etymonline.com/word/ inclusion.

3 https://dictionary.cambridge.org/dictionary/english/inclusion.

4 For a broader philosophical and historical background to the dyad of social exclusion/inclusion see Peters and Besley (2014) and on how inclusion officially emerged as a concept and social practice in the $1990 \mathrm{~s}$ see Dunne (2009). For an exploration of the conflicting philosophies within the widening participation debate see Sheeran, Brown and Baker (2007). 
the 'unusual'. Geometrically, inclusion could be depicted with being within a circle, something which is not devoid of social symbolisms and political connotations. Consider, for instance, membership in circles and aspirations to join specific circles: we find references to developing countries joining the circle of the civilized countries even in John Dewey. Dewey employed precisely this vocabulary of civilizing mission in support of a development that would make a foreign nation eventually merit inclusion in the 'civilized world' (Papastephanou, 2016 and 2017).

In my view, there are two intersecting and overlapping levels at which inclusion operates, a discursive and a material: something may be included in theoretical and conceptual works, in discourses and specific idioms, in researches and deliberation. Related theoretical and research questions are then formulated: for instance, should controversial topics find space in classroom dialogue? Is inclusion to be included in citizenship theory and are issues of rights to be included in inclusion theories (or vice versa)? Educational reforms and new recommendations also revolve around an idea or a topic meriting discursive or educational inclusion: consider as a case in point older debates on the inclusion of Environmental Education in Teacher Education curricula. But, more commonly, we talk about inclusion when someone is accepted to participate in activities and practices and to join groups, communities, states, etc., in actual life and with material, direct, measurable or immeasurable consequences for one's life. This second, more material level of relevance of inclusion has become mainstream concern in educational studies.

In some cases, membership in debates/discourses is accompanied with the material effects of the power that the newly added member has. Discursive inclusion may paradoxically entail that the new voice silences all other voices, if the new member enjoys special social status, symbolic capital and distinction in a valued social domain. Power over a collectivity may not quite or not always derive from the force of the better argument during the collectivity's deliberations and democratic decision-making. Some of the influence that a new inclusion (qua addition) in a set exerts is either because what is being said is consumable and easily heard or because it reproduces widely disseminated and established views that go down well in resonating with familiar and popular ideological positions on a topic.

Discursive or embodied ('real life', so to speak), inclusion is an act, a practice. But it is also an ethico-political term; it has both descriptive and normative functions. Like exclusion, inclusion is employed to describe the degree of permeability of a structure and the possibility of a person's or idea's positioning within or outside the structure. Such descriptions often comprise normative language concerning whether inclusion rather than exclusion should be the 
case. Furthermore, regardless of how we speak about inclusions and exclusions and of whether we are aware of them, inclusions and exclusions are also realities for some and longings for others. Some people long to be included within a valued circle or totality, whilst others, often already members of the desired totality, long for the exclusion of the aspiring candidates for membership.

In education, 'social exclusion and inclusion have emerged as strong policyleading concepts at both the national and international level in recent years' (Edwards, Armstrong and Miller, 2010, p. 417). More specifically, Michael Peters and Tina Besley (2014, p. 101) have provided valuable insight into how 'educational exclusion was outlawed and inclusive education was prescribed. Such prescription occurred through the easy adoption of legal statute and international law under a human rights framework by jurists and educators during and after the 1980s'. The process that led to this prescription 'might be described as a juridification of education as "inclusive" on the model of mainstreaming disabled students' (101).

In the current global context, as Linda Dunne (2009, p. 42) states, inclusion 'is presented as a fundamental good and worthwhile endeavour'. Based on the fact that inclusion 'may be seen as a concept that implies that nobody is excluded' (42), we may conclude that inclusion is a universalist ideal for the appropriate relationality of all human beings. Exclusion, by contrast, is a negative and regressive concept by definition. For, it 'offends against human dignity, denies people their fundamental human rights and leads, in conjunction with social and economic instability, to marginalization and deepening inequalities' (42). Ultimately, the pathologies caused by exclusion 'threaten the stability of democracy'. Therefore, as the opposite of exclusion, social inclusion 'appears to be an unconditional good' (42). I would add, inclusion may thus operate as the 'cement of society' (to use a standard sociological term).

In most related educational literature, inclusion is presented as 'a step towards social justice' (Polat, 2011), 'a crucial consideration' for providing 'equal opportunity for all pupils' (Reynolds, 2001, p. 465). There is too little doubt in educational studies about the positive qualities of inclusive talk and such doubt, when voiced at all, typically concerns (a) the applicability of the ideal of inclusion; (b) risks of conceptual and practical degeneration into undesirable doubles; and (c) unintended and pernicious power relations in schools.

(a) A doubt or reservation that is expressed in contexts of education and policy seems to reflect the following question: is inclusion applicable in all cases, regardless of the aspiring member's motivation or abilities? Am I eligible to inclusion, if I want to publish, say, in a Chemistry academic journal? A problematic situation that is often spotted, then, is the seeming paradox of inclusion as a universal right being selectively granted on preconditions of 
entitlement and eligibility. Or, it may be granted on the condition of the aspiring member's completing a process of sameness (or initiation process), that is, a process of becoming and showing proof of having become one with the existing members of the hosting community.

In some cases, the problem boils down to the normative 'common' of communities. As K. Strike (1999, p. 49) writes, 'in a community, there are not only shared tasks, there are common goods'. He applies this to education as follows: 'When teachers and students are engaged together in an educational community, they see themselves as members of a collectivity in pursuit of educational goods that they seek to achieve together' (49). Shared goods 'define the nature of a good education for members of the community. They are the source of moral coherence', which means that, ultimately, common values and principles, in being constitutive of the community, form the basis of inclusion (and exclusion). 'Educational communities are more like congregations than they are like stores or banks. They are places where people unite in common projects' (49). 'Constitutive values are often not inclusive of the diversity' (49) we find in a pluralist world. Hence the paradox: is inclusion a universalist concept, after all? If yes, then reservations of the type 'not for everyone' do not chime with inclusivist talk.

I think that a possible way out of this seeming paradox is to realize that nuance and contextualization is needed even (or precisely) when universal principles are at stake. One such nuance concerns the distinction between descriptive and normative levels of considering inclusion. Just as in the case of my publishing in a Chemistry journal, likewise, in other cases, exclusion is based on relevance in purely descriptive rather than in evaluative terms. My work, say, on the ancient Greek poet Hesiod is not necessarily unworthy from the perspective of a chemist, but it is certainly irrelevant to her research. Acceptance of my work within such a specific journal (if such acceptance were not an exception but, rather, a regular occurrence) would demolish all frames and boundaries that give to the field of chemistry its distinctiveness, that is, its diversity. Thus, my suggestion is that some cases of 'inclusion versus exclusion' dilemmas could be treated by using not qualitatively differentiated language: they require a shift from 'worthy and unworthy' to 'related or unrelated'. Inclusion may be a universalist concept in principle, but, when one approaches contexts of applicability and appropriateness of the principle, there one finds that joining a totality is not always a matter of acknowledged or unacknowledged merit. It is, rather, a matter of accepting a benign particularism as precondition for the very existence of diversity. There cannot be diverse totalities if they give up criteria and rules that reflect what binds the totality's members together and preserve its distinctiveness. 
This argument is very different from, and critical of, conservative, moralist attempts to justify 'social exclusion in terms of personal responsibility'. As Peters and Besley's apposite remark goes, much of this conservative talk refers, for example, to some people as unable or non-entitled to 'enjoy the positive consequences of economic progress due to irresponsible behaviour' (Peters and Besley, 2014, p. 105). Thus, it is important to clarify that cautious distance from acts of moralizing individual responsibility or relevance is indispensable to my argument's emphasis on the descriptive grounds of some processes of sorting out memberships and inclusions. Academically, those of us who have for years been involved in such processes, editorial, recruitment-related, etc., know too well that a facile, populist sense of inclusion that ignores relevance (e.g. of the paper submission being reviewed for publication, of the applicant's work in relation to a vacancy, etc.) is wide off the mark.

Still, the risk of including only those who are not cumbersome, dangerous or radically different, in other words, the risk of including merely the same, is not easily staved off. Inclusion is not unconditional and, from the moment that conditions are set, all sorts of issues emerge as to who has the power communicative and institutional - to define the terms and conditions of membership and participation.

Universalism may be more attainable concerning discursive inclusion (again, subject to thematic relevance), that is, concerning the critical thematization of all crucial topics of life. Neglecting nothing, thus, in principle, being open to considering just anything or, in the case of universities, researching potentially anything, entails that education, research and its agents are not immune to problematization (I use the term in Michael Peters' [2014] sense). Nothing should remain outside public and critical scrutiny. This chimes with the idea which has, as Margaret Reynolds explains, become popular that 'education for inclusion would involve the promotion of knowledge and understanding of the political life of society with attendant rights and responsibilities' (Reynolds, 2001, p. 466). Nevertheless, even if such all-round visions of ever enlarged thought were to bring the ideal of the educated citizen and the knowledgeable person closer to approximation, it does not suffice to create a better political world. To push this further, discursive inclusion, enlargement of thought and knowledge does not automatically translate into better world politics and embodied, material inclusions. Embodied inclusion is universalist in some cases (e.g. democratic governance, asylum and residency rights, human rights-based membership or entitlement of benefits), etc. But there are cases of embodied inclusion where universalization is not only inapplicable but even politically problematic (for such a case, see my discussion of the Chagos issue in Papastephanou [2018]). 
Hence, the neutrality between competing conceptions of the good that I see as applicable to some issues of inclusion or exclusion is not entirely relevant. In some cases, inclusion in a host country or community may operate as a red herring, diverting attention from other, more demanding normativities, e.g. from debts owed to alterity and from other obligations to a wronged or unjustly treated alterity (Papastephanou 2018). In other cases, there should be normative criteria of membership and expectations from the prospective new member, even confrontational, dialogical engagement with the other. Certainly, all this is far from settling difficult issues of inclusion and its applicability; but it is included in my account here as politically more promising than lukewarm, abstract celebrations of inclusion understood as offering a safe haven of disengaged acceptance to just any alterity. Keeping one too safe, protecting people or groups from one another, not making demands on the other is, in my view, a subtle form of racism. It is so because it amounts to considering the other incapable of the justice that you deem yourself capable of.

(b) Doubt about the positive qualities of inclusive talk is also expressed concerning the risks of sliding into undesirable doubles that inclusion faces. A relevant rhetorical operation that I notice in much related literature is to accompany inclusion with a like-sounding yet bad noun and a question mark: e.g., 'inclusion or intrusion?', and 'inclusion or delusion?'. Such operations point to practical failures to live up to the normativity of the concept: inclusive discourse may overlook the imposition of new, unjustified boundaries or the wiping out of justified boundaries. In such cases, I think, we could talk about true inclusion and pseudo-inclusion, but issues of who draws this line and how are beyond the scope of this article.

(c) A third doubt (or reservation) concerns the power relations which frame inclusion: 'whose interests are served by the way that inclusion is spoken about and (re)presented in schools?' (Dunne, 2009, 42). An alarming answer is that the interests of the hosts are served. Here is Gert Biesta (2009, 101): 'although attempts to make democracy more inclusive are laudable, they are ultimately based upon a colonial conception of democratisation'; within it, 'inclusion is seen as a process where those who are already on the inside include others into their sphere'. On her part, Dunne (2009, 42) explains her increasing unease with the concept of inclusion as follows: 'the ways that children are spoken about, positioned and "managed" in schools in the name of inclusion, however seemingly altruistic and well meaning, are not benign and can have disciplinary effects'.

It is hard to dispute that 'established discourses, such as the discourse of inclusion, are employed by various regimes of power and are subjected to 
investment and control' (Dunne, 2009, 44). In fact, we may push this further to draw attention to the fact that inclusivist talk establishes a community of right-thinking people, entitled and eligible to discuss and promote inclusion and obtaining praise, academic visibility and distinction by doing so. This recently produced 'we' presupposes as its dialectical opponent those 'others' who are ideologically attached to regressive and pernicious ideals, those lagging behind the advanced, progressive scholar or those who simply fail to show that they are up-to-date or to jump on the bandwagon of capitalizing on the prospect of including the excluded.

To sum up, most of the above doubts may be encapsulated in this formulation: 'when we talk of including, who do we include and into what do we seek to include?'5 - meaning that inclusion does not entail the quality or the transformation of the structure into which the new member is placed. In the section below, I attempt to reveal more complications by going beyond this formulation (while keeping it in view) and by reversing some of the related questions.

\section{Who Wants to be Included? Who Seizes Discursive Power?}

A question that seems acceptable to ask has so far been: inclusion of who into what? But this seems to exhaust the reservations and reticence of researchers. Many academics who engage in political education or educational policy seem to assume that the utmost good for a person is to be included. Those who make this assumption without asking the 'into what' question forget that, since Hegel's vision of the Absolute as the spirit's return to an undifferentiated unity (for what was this, other than a frightening prospect of an inclusion absorbing and annihilating diversity?), we may no longer turn an innocent, unsuspecting eye to pleas for all-encompassing, all-embracing, seemingly benevolent treatments of alterity. Inclusion does not entail acknowledging the value of difference and exerting generosity, kindness, hospitality, open-mindedness and various ethical, political and intellectual virtues.

Those who are more aware of dangers of romanticizing the inclusion into an unchanged or unchallenged host totality continue, nevertheless, to presuppose - as I see it - that the utmost good for a person is to be included and, by implication, the worst thing is to be excluded. It is especially so, if the host totality is considered a transformative and worthy one (that is, if the 'into what' questions has been answered in rosy terms for the host collectivity).

5 For a similar question, see Graham and Slee (2008, p. 277). 
In making such assumptions about the subject aspiring to be included, theorists, public personae and policy makers contribute to the promotion of the social interpellation to be included. Simultaneously, they fail to give due attention to self-exclusion, to withdrawal and conscious retreat as a virtue and as a potentially valuable political stance. One may not want to be included (and, for that matter, included by invitation or by obligation or by necessity) in a way of life, in a dialogue or in a community or process for various reasons. Some such reasons may not only make sense but even set a good example that halts the obsession with belonging, with not being left out or with not lagging behind.

Still, in my view, withdrawal should not be romanticized either. Selfexclusion may sometimes result from operations of 'othering' those who constitute members of a totality. The self may narcissistically exaggerate her distance from the totality and her difference from its members to find precisely self-vindication in the dark depiction of such a collective otherness. A subject can find safety and reproduce her own comfort zones when included and, sometimes, even when excluded or self-excluded. The entrapment in the 'inclusion-exclusion' dichotomy and the limitation of politics to such stakes block insight into principles and virtues that cannot be channeled into the 'inclusion versus exclusion' preoccupations. Ultimately, they block awareness of a relationality that is more demanding on both sides, the totality and the singularity joining it, and that invites or requires those unsettling and destabilizing experiences that shake the ego and draw you into something better.

From my point of view, then, the questioning of inclusion exclusively from the perspective of what exclusions may accompany inclusion or come in as a side- or after-effect still operates within the confines of the 'inclusion/ exclusion' and 'insider/outsider' dichotomy, as if the worst thing that can happen in life is to be either subtly or blatantly excluded. By implication, it is not surprising that, in diagnostics of current global pathologies, the metaphor of gate-keeping emerges as the major problem that the Western researcher can notice and appreciate in the world of today.

Constructions such as 'education for inclusion and diversity' or 'education for inclusion and democracy, equity, citizenship, etc.', subordinate education to a single normative concept, a single ideality, namely, inclusion, from which all else is expected to emanate. No wonder, then, that, in the 199os, 'issues about gender, race, disability and class seem to have combined within a more global concern for the provision of inclusion' (Reynolds, 2001, p. 466).

The academic popularity of inclusion excludes a whole family of other normative terms (thus, it fails at the level of discursive inclusion). Other normativities (international right, redistribution of wealth, egalitarianism, educational offset of uneven cultural capital effects) no longer receive due attention; 
or, when they are included in discourses, they are approached through the framework of inclusion, as if they were mere cognates of this notion. I object to the reduction of political vision to merely including otherness because, I argue, this reduction results in failure to consider more concrete and material political measures such as environmental policies on grounds of nonanthropocentric ideality, settlement of damages of global conflicts on grounds of pending historical ethico-political debts, global redistribution of wealth on grounds of justice beyond self-congratulatory framings of charity and aid, etc. Also, inclusivist politics fails to cultivate daily awareness of issues which, had they been known or declared as problems of global and environmental justice, they would have constituted higher political demands than simply enlarging the numbers of 'we'.

From my perspective, a major problem is the 'as if' that underpins inclusion discourses, the fact that we talk about inclusion as if there is no other request to us, human beings, but to form porous, permeable circles as our hives, or to use Karl Jaspers' term, as our 'shells' (Jaspers, 1925, p. 181). Hence, I suggest some critical revisiting and some consideration of what our fixation on inclusion may exclude (including consideration of the neglect, i.e., the exclusion, of what lies outside the 'exclusion versus inclusion' dichotomy). In the rest of this article, I turn the attention to who is included, what may be excluded and who seizes discursive power in debates on teachers, education and teacher education.

\section{$4 \quad$ Inclusion and Public Debates on Teaching and Teachers}

Implications of hegemonic framings of inclusion can be drawn from public discourses. Politicians' statements and interventions, party politics on education, media and educational policy texts are discourses, that is, 'social practices that represent social realities in particular ways, and construct particular social positions'. They are public discourses 'in that they are constructed in, and circulate within, the public sphere' (Thomas, 2011, p. 372). Let me begin with some general remarks on public debates about education, before moving to how I read this issue from an educational-philosophical perspective on inclusion.

The context of public debates on education involves the fact that 'the 21st century is a media-saturated world' in which the media, notably television and Internet, are 'central to public life' (Thomas, 2011, p. 372). Within such a context, the public interest in education and, especially, in teacher education has been expressed with unprecedented passion: 'there have never before been such blistering media commentaries and such highly politicized battles 
about teacher education as those that have dominated the public discourse and fueled legislative reforms' in recent years (Cochran-Smith and Fries, 2001, p. 3). This holds true not just with regard to national public debates but also with regard to the European context, which has its own specificity and presents particular challenges to inclusion and participation in public opinion shaping. For, 'the mass media public sphere on which European political communication relies even more than national political communication is a highly competitive environment in which actors compete for limited public visibility, resonance and legitimacy' (Koopmans, 2007, p. 205). However, debates on educational matters are more than Europeanized. They are, indeed, globalized. Public debates about teacher quality abound and have been prominent (Thomas, 2011) worldwide.

Inclusion in public debates is seemingly unconditional, democratic and unrestricted by specialization, as more and more non-educationists such as economists, administrators, politicians, media personae and think tanks feel entitled to speak (and take such a liberty) about the 'trials' of education and the 'deficits' of teacher performance. But, if we 'read' the whole issue in more awareness of ambiguities of inclusivity, we will realize that the realities underneath public interest in education are more complex. In my view, relevant interrogations of possible future research on education should include questions such as: what is excluded from public debates or initiatives? Who is included in public discourse? Who is publically though tacitly granted investigative force? And, who has true discursive influence on issues of education?

Let us begin with the fact that, though inclusion becomes an important aim of educational policy initiatives, 'government directives often miss essential elements in the provision of inclusion' (Reynolds, 2001, p. 468). In other words, material, embodied inclusion (that is, inclusion of diversity in schools) founders inter alia on what I have above theorized as discursive exclusions. For instance, educational policy and related initiatives 'do not include the educational and evaluative principles underpinning practice' that is appropriate and enabling of material inclusion. On the contrary, they exclusively emphasize standards that 'detail the skills and knowledge required for accreditation purposes' (Reynolds, 2001, p. 470). We also notice significant and telling discursive exclusions ${ }^{6}$ when public opinion and/or educational systems focus on the teacher as the determining factor of student performance. Teachers are given

6 Another discursive exclusion that I see as relevant - though I cannot unpack it in this article for reasons of length - concerns the fact that, in eudaimonic approaches to education and well-being, the latter is singularized as the well-being of students. The well-being of teachers is not considered in both the related research and the concomitant public debates. On this 
a dual role: they are the main cause of low outcomes and, at the same time, they are singled out as those who can raise standards. Their education is more and more designed along such a narrow scope. 'Any attempt to promote less tangible aspects of teacher education, such as professional values, would be problematic in a system that is output driven' (470).

Educational research shows that 'different discourses and genres of media and policy texts' collaborate 'to construct authoritative, public commonsense discourses about teacher quality, in which teachers' are represented 'as lacking in the qualities expected of the good teacher and as needing to lift professional skills to improve educational standards' (Thomas, 2011, p. 372). Thus, the nonmeasurable is excluded to more general effect. Those who shape public opinion are incurious about non-individualized factors of student performance that require non-moralist and enlarged perspectives that are resistant to quantification. The self-declared experts along with the non-experts (e.g. media actors) who dominate public debates exclude from their scope and from public coverage questions such as: through what genealogies do some students end up lagging behind? What surplus of social and political responsibility beyond mere inclusion do such genealogies indicate? These questions, along with other complex issues and realities that make the work of teachers neither as fulfilling nor as felicitous as teachers would want, are discursively excluded. They remain outside the scope, literally and theoretically, of the neoliberal managerial eye.

The public interest in education - an interest that may be otherwise wellmeant and welcome - is nevertheless strongly influenced by claim-making power. The latter is diversified and involves 'strategic action in the public sphere'. Diverse interests are expressed when various actors exert public communicative power through their purposive, open articulation of political demands, criticisms, calls to action or recommendations. All these 'affect the interests or integrity of the claimants and/or other collective actors' (Koopmans, 2007, p. 189). 'Which actors are most effective in making their mark on public debates' (194) relates to the issue (of the previous section) about who wants to be included and who manages to turn communicative power into institutional power most effectively in relation to educational stakes.

Therefore, inclusion of teachers' depictions in media (e.g. television sitcoms) that scapegoat them (Thomas, 2011); output-driven inclusive educational policy discourses (Reynolds, 2001); and inclusion of non-specialized actors in public opinion-formative constructions of the image of the teacher may

point, I am indebted to Dr Christina Mavropoulou who has drawn my attention to this fact. For more on this fact, see Mavropoulou's PhD thesis (2017). 
synergize in reducing the claim-making power of educators, despite the fact that education is the issue field of their specialization. Two caveats here: I am not saying that the educators' voice should be unquestioningly authoritative due to their specialization. Nor am I saying that educators (teachers and other professionals in educational theory and practice) are univocal. I am rather saying that, as a collectivity of experts, and despite the ostensible openness and unconditional inclusivity of the public sphere (i.e., in principle, everybody can air her views on education), educators are less audible than other, more powerful actors. Research shows, for example, that nationally confined public debates clearly operate in favor of 'actors who command strong institutional power' (Koopmans, 2007, p. 194). And further evidence shows that the Europeanisation of public debates exacerbates these power differentials. Adapted to the educational context, this makes us suspect that the actors who manage to cross the boundaries of national public spheres are not those who are actively involved in educational theory and practice. Indeed, as Ruud Koopmans argues, the true boundary crossers are 'overwhelmingly core executive actors such as heads of government and cabinet ministers' (196). Educators and their union representatives make 9 per cent of the purely national claims on education (i.e., 'in the issue fields where they are strong') against 5 per cent of Europeanised claims on educational matters (200). Thus, educators 'are extremely weakly represented in Europeanised public debates' (183). 'Government and executive actors are by far the most important beneficiaries of the Europeanisation of public debates compared to legislative and party actors, and even more so compared to civil society actors' (183) such as educators.

Unqualified inclusion of various agents, fora, international organizations and think tanks in public discussions on education, on teachers and on their education has legitimized new distributions of communicative power that are far from fair or balanced. This is not merely an issue of inclusion deficits in public debates that could be remedied by more inclusion. Inclusion concerns the question about the frequency with which some issues and interested social agents pass the selection filters of the public sphere and make their mark on public debates. There may be various practical and applied-politics means of enhancing the voice of civil society actors who are currently 'clearly the least able to profit from the opening up of Europeanised discursive spaces' (Koopmans, 2007, p. 199). But this is not the point of this article. 'Which actors populate the Europeanised public sphere' (Koopmans, 2007, p. 200) is, from my perspective, an example of how inclusion relates to the discursive relevance that I theorized in an earlier section and to self-exclusion as a virtue. Hence, the issue that this article thematizes is that, apart from considering ways of more inclusion or empowerment of the voice of people inhabiting specialized 
fields, there should be another challenge to education. People (especially those who have ex officio more discursive influence, namely, politicians, executives, media actors, etc., though less knowledge about educational matters) may have to be educated about the importance of self-exclusion on grounds of discursive relevance or pause for thought and of the self-restraint that enables one's harkening to the specialist's voice.

The discursive influence of educators is more limited than those of politicians and media actors (Koopmans, 2007, p. 199). Sometimes, 'governments court media to influence public support for education policy' (Thomas, 2011, p. 372), and this makes the power of the synergy of politicians and journalists more evident. Politician or journalist, anyone who may (nominally or genuinely) promote inclusion, justice and other values may simultaneously feel interpellated to be included in public discourses on education. Such agents eventually become active, authoritative and decisive voices in public debates on education. They are not hesitant or reluctant to be included in those who claim investigative force on issues of education quality and who engage in finger-pointing and in teacher blanket incrimination. Thus, what at first sight appears to be a democratic issue of inclusion of the lay voice against specialists or professional élites and an opening up of the public sphere to other voices on educational matters, and could be heralded as a sign of more inclusion, can and should be read in a rather subversive way: it is problematic from the normative perspective of democratic legitimacy and discursive influence.

It is always important to acknowledge, along with Michel Foucault, that 'exclusion operates spatially in the development of all-seeing architectures that permit continual surveillance' (Peters and Besley, 2014, p. 102). Through dividing practices, exclusion separates 'a series of others who represent a danger to the body of society' (102). I have, with this article, tried to show the other side of the coin, namely, that the production of society is often effected through unqualified inclusion rather than through direct exclusion. From this perspective, not the prohibition of discussing certain topics but their thematization indicates a procedure of inclusion which is no less problematic than exclusion as such. The more openly education is being discussed, the more the public sphere is one-sidedly led to sweeping generalizations. This is certainly not an argument against thematization and problematization; it is a criticism of the way that the problematization of education is being carried out. When educational accountability is at stake, teachers are turned into scapegoats and structural, societal pathologies are obscured.

European fora and organizations disseminate statistics with numbers of successful and unsuccessful schooling, expensive education or education making economic sense. Measuring, along with the measurable, becomes 
all that matters in what people imagine as a world of education. The 'evidentiary warrant', "what the evidence actually says" about teacher education' (Cochran-Smith and Fries, 2001, p. 4), ${ }^{7}$ thus obtains unconditional value to obsessive effect and establishes new power mechanisms. Economists, lawyers, managers, doctors and other burghers want to know more about education and, much more, they want to have their own share in the shaping of it, often in the name of the tax-payer. Being tax-payers themselves, and thus being 'the lifeblood' of the educational system, they consider it their right to have a say on education, in other words, to be included in an ever enlarged circle of those who influence public discourse on education. They do not want education to be a kind of dark zone nor even something independent from the administrative panoptical gaze. This desire to know, this will to truth (in fact, this desire for half-truths, post-truth and untruth) involves a twist from mechanisms designed to exclude to mechanisms designed to include those who wish and can exert a control that impoverishes educational public discourse.

Unqualified and unrestrained inclusion has led to the emergence of a new set of agents, a new particularist community, those who use the benefit of being overrepresented in public debates to criticize educators (the underrepresented in public claims-making) sweepingly. Little self-restraint or pause for thought is noticed when social agents who know too little about education nevertheless feel entitle to speak about it and make judgments or recommendations that shape and direct public opinion. The limits of their own field (e.g. the exclusive emphasis on quantification and measurement that, applied to other fields, leads to uncritical and wrong conclusions) are, to them, the limits of the world. The extremely weak representation of educators (as civil society actors) in national, in Europeanized (Koopmans, 2007) and in some non-European public debates (Thomas, 2011) compared to that of politicians, executives, media actors, and other such non-directly related to education social agents confirms, to use Habermas' parlance, that societal systems such as economy and administration colonize the lifeworld. In other words, the educational zone of societal space becomes more porous and non-exclusionary of concerns that older educational ideals would have set aside as too 'interested' and instrumentalizing of education.

The assumption that the right to be included is all that the other seems to expect from 'us' and the implicit assumption that the duty to include the other exhausts the scope of Western citizens' responsibilities and potentialities are

7 Cochran-Smith and Fries use the term 'generally to refer to the set of justifications and grounds that are offered for conclusions and policy recommendations based "entirely" (or at least purported to rest entirely) on empirical data, evidence, and facts' (2001, p. 5). 
also evident in many public discussions of multikulti education or of 'no child left behind' sloganeering and in educational policies and initiatives. It feels as if no other obligations or mobilizations are required beyond acknowledging universal rights of schooling, residence, citizenship, quasi-egalitarian formalism, and so on. But, even the attention to the student (to be included) and the teacher (who will include or teach for inclusion) is too uniform, homogenizing and deep-down convenient for Western consciousness.

For example, as Margaret Reynolds shows in her critical association of inclusion with discourses on equal opportunities and teacher training agencies, the teacher is expected to foster values compatible with inclusion, yet the public (and related policy fora) understands the teacher more as a practitioner (i.e., the emphasis is on practical competence) than as a critical thinker called to teach or to cultivate complex values (Reynolds, 2001). This is also reflected in teacher training priorities: "little emphasis has been placed on the evaluation of the "how" or tenor of practice, rather than merely the "what" of performance' (469).

When inclusion is viewed as unconditional right, which is an important move on many accounts nevertheless, this often leads theorists to losing sight of the fact that a right requires choice. A basic quality of a right, namely, to be exercised in freedom, to be an individual's option, presupposes that our global responsibilities do not end in acknowledging a right to join a totality but go deeper. They involve demands of nothing less than the kind of world change which would give people true choice whether to seek membership or to stay outside. In the case of students this means to have a true choice of learning, though the intricacies of this statement make it an almost impossible claim, at least one that cannot be raised here lightheartedly. But the issue of choice also reflects on discursive inclusion in ways that are more manageable within the context of this article. As Zdenko Kodelja (2016), reminds us, the concept of rights presupposes that the subjects of rights have the liberty to decide for themselves whether to exercise their rights or not. Self-restraint does not mean that you give up a right in principle but that you judge on the temporal, situational and thematic appropriateness of exercising it. This is a kind of application of the idea of discursive relevance that I have deployed in a previous section: we should exert our right to inclusion in public dialogue subject to considerations of the discursive relevance of our voice. Such considerations that we should carry out ourselves may sometimes lead us to suspending the exercise of our right to speak and to researching more deeply on a topic, prior to giving public verdict and to claiming for ourselves the right to judge.

An understanding of educational globality beyond the confines of benevolent inclusion is crucial for creating conditions of true choice between the 
right to be included and the right to remain silent. It is crucial to action itself, because, harkening to diverse voices, paying attention to diverse and complex reasons underneath educational realities facilitates awareness of diversified obligations and responsibilities. The latter range from easy responsibilities of granting inclusive, empowering education to more difficult ones of pressing a global public sphere toward creating more enabling socio-political conditions for transformative education and for resisting the sweeping effects of the very interpellation to be included.

\section{5}

\section{Conclusion}

'In the context of public debates on teacher quality, both media and education policy texts construct deficit discourses about teachers, discourses that work together to inform public, commonsense understandings of teacher quality' (Thomas, 2011, p. 371). In becoming a 'policy problem' (Peters et al., 2017, p. 1), education in general and teacher education in particular have suffered a coercive objectification. Despite the verbal emphasis on inclusion, discursive exclusions are being reproduced. Important societal factors, unrelated to teachers, yet blocking the approximation of the ideal of student inclusion and of the educational values that are not reducible to inclusion, remain unseen by the public eye.

I have used the example of public debates to illustrate some ambiguities of the notion of inclusion. I have argued that agents making a mark in discourses of educational reform are contradictory as concerns the right to inclusion which they claim and exercise by joining educational debates and the exclusions of the professional voice that their inclusion ultimately effects. But I have not claimed that professional groups and/or educational élites should have the exclusive power to direct debates and reforms in their field. I have argued, instead, that educators' and other relevant professionals' arguments remain outside the purview of those who now dominate the debates on the politics of teacher education either due to complexity or due to divergence from the ideological priorities of neoliberalism.

To conclude, let me sum up my main points. Inclusion as a liberal value is broadly employed as a standard, major and indisputable good. The only or the main question/challenge seems to most academics to be how to make inclusive practice more common and effective. In this article, I have tried to complicate the notion of inclusion. As some skeptical thinkers argue, inclusion may be a conservative value, if it means that all that is at stake is to give somebody space within an unaltered reality. But, I have argued, there are other 
problems too, a major one being that the overemphasis on inclusion blocks insight into other, broader tasks. For instance, it may sometimes be important to exert a temporary self-exclusion from public discourses, a kind of pause for thought. The latter may facilitate engagement with dialogue as a will- and opinion-formative medium rather than as a vehicle for promoting ideologically imbued, competing agendas. The entrapment in the framework of 'inclusion versus exclusion' obscures a perception (and concomitant political education) of varying political responsibilities in plural and of virtues such as self-restraint. Though admirable (and, sadly, as yet unmet), the urge/exhortation to include is not exhaustive of human responsibilities. As too minimal a demand, and when not accompanied with any other ethico-political expectations, inclusion operates in politically soporific ways. Hence, it may be worth trying to position inclusion within a broader set of concepts and to associate it with a family of virtues that are important for a desirable redirection of political education.

\section{References}

Cochran-Smith, M., \& Fries, M.K. (2001). Sticks, stones, and ideology: The discourse of reform in teacher education. Educational Researcher, 30(8), 3-15.

Dunne, L. (2009). Discourses of Inclusion: a critique. Power and Education, 1(1), $42-56$.

Edwards, R., Armstrong, P., \& Miller, N. (2001). Include me out: critical readings of social exclusion, social inclusion and lifelong learning. International Journal of Lifelong Education, 20(5), 417-428.

Graham, L.J., \& Slee, R. (2008). An illusory interiority: Interrogating the discourse/s of inclusion. Educational Philosophy and Theory, 40(2), 277-293.

Jaspers, K. (1925). Psychologie der Weltanschauungen. Berlin: Springer Verlag.

Kodelja, Z. (2016). The Right to Education and Global Distributive Justice. In: Strand, T., Smith, R., Pirrie, A., Gregoriou, Z., and Papastephanou, M., eds., Philosophy as Interplay and Dialogue (Berlin: LIT Verlag).

Koopmans, R. (2007). Who inhabits the European public sphere? Winners and losers, supporters and opponents in Europeanised political debates. European Journal of Political Research, 46(2), 183-210.

Mavropoulou, C. (2017). Is open-mindedness necessary for intellectual well-being in education? Bringing together virtue, knowledge and well-being in initial teacher education (Doctoral dissertation, University of Edinburgh).

Papastephanou, M. (2016). Genocide, Diversity, and John Dewey's Progressive Education. Metaphilosophy, 47(4-5), 627-655. 
Papastephanou, M. (2017). Learning by Undoing, Democracy and Education, and John Dewey, the Colonial Traveler. Education Sciences, 7(1), 20-33.

Papastephanou, M. (2018). Terror(ology) in the Time of 'Cosmopolitanism'. Knowledge Cultures, 6 (3), 7-27.

Peters, M.A. (2014). Problematizing Liberal Cosmopolitanisms: Foucault and neoliberal cosmopolitan governmentality. Contemporary Readings in Law and Social Justice, $6(1), 13-37$.

Peters, M.A., and Besley, T.A. (2014). Social exclusion/inclusion: Foucault's analytics of exclusion, the political ecology of social inclusion and the legitimation of inclusive education. Open Review of Educational Research, 1(1), 99-115.

Peters, M.A., Cowie, B. and Mentor, I. (2017). (Eds.) A Companion to Research in Teacher Education. Singapore: Springer.

Polat, F. (2011). Inclusion in Education: A step towards social justice. International Journal of Educational Development, 31(1), 50-58.

Reynolds, M. (2001). Education for inclusion, teacher education and the teacher training agency standards. Journal of In-Service Education, 27(3), 465-476.

Sheeran, Y., Brown, B.J., and Baker, S. (2007). Conflicting philosophies of inclusion: the contestation of knowledge in widening participation. London Review of Education, $5(3), 249-263$.

Strand, T. (2015). Thinking Democracy and Education for the Present: The Case of Norway after July 22, 2011. https://www.duo.uio.no/bitstream/handle/10852/47772/1/2015 .Thinking\%2BDemocracy\%2Band\%2BEducation\%2Bfor\%2Bthe\%2BPresent.pdf. Downloaded: 30 October 2018.

Strike, K.A. (1999). Can schools be communities? The tension between shared values and inclusion. Educational Administration Quarterly, 35(1), 46-70.

Thomas, S. (2011). Teachers and public engagement: An argument for rethinking teacher professionalism to challenge deficit discourses in the public sphere. Discourse: studies in the cultural politics of education, 32(3), 371-382. 